\title{
Abdominal Obesity and low grade Systemic Inflammation as Markers for Subclinical Organ Damage in type 2 diabetes
}

Elsa M Dahlén, Toste Länne, Birgitta Clinchy, Jan Ernerudh, Fredrik Nyström and Carl Johan Östgren

\section{Linköping University Post Print}

\section{Tweet}

N.B.: When citing this work, cite the original article.

Original Publication:

Elsa M Dahlén, Toste Länne, Birgitta Clinchy, Jan Ernerudh, Fredrik Nyström and Carl Johan Östgren, Abdominal Obesity and low grade Systemic Inflammation as Markers for Subclinical Organ Damage in type 2 diabetes, 2014, Diabetes \& Metabolism, (40), 1, 76-81. http://dx.doi.org/10.1016/j.diabet.2013.10.006

Copyright: Elsevier Masson http://www.elsevier-masson.fr/

Postprint available at: Linköping University Electronic Press

http://urn.kb.se/resolve?urn=urn:nbn:se:liu:diva-71401 


\section{Abdominal Obesity and low grade Systemic Inflammation as Markers for Subclinical Organ Damage in type 2 diabetes}

E. M. Dahlén ${ }^{\mathrm{a}}$
A. Tengblad ${ }^{\mathrm{a}}$
T. Länne ${ }^{\mathrm{a}}$
B. Clinchy ${ }^{\text {b, c }}$
J. Ernerudh ${ }^{\text {b, c }}$
F. H. Nystrom ${ }^{\text {a, d }}$
C. J. Östgren ${ }^{\mathrm{a}, \mathrm{d}}$

a) Department of Medical and Health Sciences, Linköping University, Linköping, Sweden

b) Department of Clinical and Experimental Medicine, Division of Clinical Immunology, Linköping University, Linköping, Sweden

c) Department of Clinical Immunology and Transfusion medicine, Linköping University Hospital, Linköping, Sweden

d) Diabetes Research Centre, Linköping University Hospital, Linköping, Sweden Corresponding author:

Elsa M Dahlén, Department of Medical and Health Sciences, Division of Community Medicine

Linköping University

SE-581 83 SWEDEN

fax +4613224020 tel +46704787325

Email: elsa.dahlen@liu.se

Word count summary: 209 words, Word count text: 2218 words , Tables: 3, Figures: 1 


\section{Summary}

Aim:

The aim of this study was to explore associations between abdominal obesity, inflammatory markers, and subclinical organ damage in 740 patients with type 2 diabetes.

Methods:

Waist circumference (WC) and sagittal abdominal diameter (SAD) was measured. Blood samples were analyzed for; C-reactive protein (CRP) and IL-6. Carotid intima-media thickness (IMT) was evaluated by ultrasonography. Aortic pulse wave velocity (PWV) was measured with applanation tonometry.

Results:

Abdominal obesity measured as SAD and WC were significantly correlated with; IL-6 (WC $\mathrm{r}=0.27, \mathrm{p}<0.001, \mathrm{SAD} r=031, \mathrm{p}<0.001), \mathrm{CRP}(\mathrm{WC} r=0,29, \mathrm{p}<0.001, \mathrm{SAD} \mathrm{r}=0,29, \mathrm{p}<0.001)$, IMT (WC r=0.09 p=0.013, SAD r=0.11, p=0.003) and PWV (WC r=0.18, p<0.001, SAD $\mathrm{r}=0.21, \mathrm{p}<0.001)$. In multiple linear regressions with IMT or PWV as dependent variable and age, sex, statins, systolic blood pressure (SBP), Body Mass Index (BMI), CRP and HbA1c, as independent variables, both SAD and WC, remained associated with IMT and PWV. In stepwise linear regression, entering both SAD and WC, the association between SAD and PWV was stronger than the association between WC and PWV.

Conclusion:

We conclude that SAD and WC are feasible measures of obesity that provides information on inflammation, atherosclerosis and arterial stiffness in type 2 diabetes. However, SAD was slightly more robustly associated to subclinical organ damage, compared with WC. 
Keywords: Type 2 diabetes; Obesity; Anthropometric measurements; Cardiovascular Disease

\section{Introduction}

Cardiovascular disease (CVD) is the major cause of morbidity and mortality in patients with type 2 diabetes (1). Traditional risk factors such as high LDL cholesterol and low HDL cholesterol, hypertension and smoking do not fully explain the increased cardiovascular risk in patients with type 2 diabetes (1). Therefore, it is of great importance to identify clinically feasible, cheap and non-invasive risk factor assessment tools to predict CVD.

Low grade inflammation is suggested to be involved in the atherosclerotic process and it has previously been shown that patients with type 2 diabetes present with higher levels of inflammatory markers compared to subjects without diabetes (2).

Continuous deposition of oxidized lipoproteins in the vascular wall leads to an inflammatory response from the endothelial cells which send signals to monocytes that transforms into macrophages. However the macrophages can scavenge the lipoproteins and form foam cells that leads to fatty streaks in the vessel wall. This is the initiation of the cascade of events that eventually leads to atheroma formation in the arterial wall (3). But the macrophages not only form fatty streaks, they also secrete pro-inflammatory cytokines (4). Systemic low grade inflammation can be measured as circulating levels of the acute phase reactant CRP or by levels of pro-inflammatory interleukin (IL-) 6.

Development of type 2 diabetes is closely associated with obesity and abdominal obesity is the best obesity-related predictor of type 2 diabetes (5). Anthropometric measures are useful in clinical practice since they are both non-invasive and cheap. Waist circumference (WC) is 
currently the most commonly used measurement for abdominal obesity, and highly associated with the risk of developing CVD. However, recent studies suggest sagittal abdominal diameter (SAD) to be a better measurement to assess an adverse metabolic profile (6-8).

Intima media thickness (IMT) of the carotid arteries measured by high resolution B-mode ultrasound is a widely accepted non-invasive marker of subclinical atherosclerosis (9). In addition, in view of its correlation with coronary atherosclerosis and its capacity to predict incident coronary events, carotid IMT has been proposed as a surrogate marker of coronary atherosclerosis (10). Also pulse wave velocity (PWV) measured by tonometry provides a noninvasive estimate of arterial stiffness and is an independent predictive risk factor for all-cause mortality and cardiovascular mortality (11-13).

The aim of this study was to compare two different anthropometric measures, WC and SAD, of abdominal obesity with regard to low grade systemic inflammation and subclinical organ damage in terms of atherosclerosis and arterial stiffness in a middle aged cohort of patients with type 2 diabetes. In addition, we wanted to explore the association between markers of low grade systemic inflammation and subclinical organ damage in this cohort.

\section{Methods}

We analyzed baseline data from 740 patients, who participated in a community-based cohort study, CARDIPP (Cardiovascular Risk factors in Patients with Diabetes - a Prospective study in Primary care). CARDIPP was launched in 2005 and completed in 2008 with the aim to identify markers for cardiovascular disease to facilitate earlier and individually adjusted interventions, in middle aged patients with type 2 diabetes. CARDIPP comprises data on an extended annual follow up on patients with type 2 diabetes, aged 55-66 years, consecutively 
recruited from 25 different primary health care centers in the counties of Östergötland and Jönköping, Sweden. Detailed information about the structure and results from CARDIPP has been described previously (14-15). The centres were located in different demographic areas and differed in size. However, the model of treatment and care of type 2 diabetes was organized similarly and all primary care centres adhered to the same national guidelines of diabetes care. 761 patients participated in CARDIPP through November 1, 2008. Due to missing data in 21 cases, the present cohort was confined to 481 men and 259 women.

\section{Anthropometric measurements}

Nurses specially dedicated to treatment of diabetes at the primary healthcare centers, measured blood pressure after 5 minutes of seated rest. The mean of three consecutive readings was used. Height (to the nearest $\mathrm{cm}$ ) and weight (to the nearest $0.1 \mathrm{~kg}$ ) were also measured with the patients wearing light indoor clothing. Waist circumference (WC) was measured with the patient standing, after a regular expiration, to the nearest $\mathrm{cm}$, midway between the lowest rib and the iliac crest. SAD was recorded with the patient in the supine position and with bent knees, with a standardized sliding beam calliper at the highest point of the abdomen.

The investigation also included a standardized medical history, including data on diabetes duration and ongoing medication.

\section{Laboratory tests}

Blood specimens were drawn in the morning after a 10 hour over night fast. Routine tests such as HbA1c, plasma glucose and serum lipids were analysed according to routines at the primary health care centres. HbA1c was analysed according to the Swedish Mono-S HPLC 
standard, which is approximately $1 \%$ below the DCCT standard. Blood samples were frozen for later analysis of high sensitive C-reactive Protein (CRP), apoB, apoA-I and cytokines at the Centre for Laboratory medicine, Linköping University Hospital, Linköping, Sweden. CRP values above $10 \mathrm{mg} / \mathrm{ml}$ were excluded from the analyses according to current guidelines (16). Plasma levels of IL-6 and IL-10 were measured with an ultrasensitive cytokine bead kit (Invitrogen Co, Carlsbad, CA, USA) according to the manufacturer's instructions and analyzed on a Luminex ${ }^{\circledR} 100^{\mathrm{TM}}$ system (Austin, TX, USA). The limit of detection was 0.84 and $0.68 \mathrm{pg} \mathrm{ml}^{-1} \mathrm{IL}-6$ and IL-10, respectively. Intra-assay coefficient of variation (CV \%) was 5-12\% and inter-assay was $17-20 \%$.

\section{Physiological vascular examinations}

The carotid ultrasonographic investigations, PWV and SAD measurements were performed at the Department of Physiology, Linköping University Hospital, Linköping Sweden and at the County Hospital Ryhov, Jönköping, Sweden. The IMT of the carotid arteries was evaluated using a B-mode ultrasound. A digital ultrasound system (ATL HDI 5000, Bothell, WA, USA) equipped with a broadband linear transducer (L12-5) was used for scanning the carotid artery in longitudinal section. ECG leads were connected. For lumen diameter (LD) and IMT determination, during diastole, three consecutive frozen images with special focus on lumenintima echo and media-adventitia echo of the far arterial wall were saved for later analysis. The digital B-mode images were subsequently transferred to a PC, where software for off-line measurement of LD and IMT is installed (Artery Measurement System II, Image and Data Analysis, Gothenburg, Sweden). Calibration and subsequent measurement was performed by manually tracing a cursor along the leading edge of the intima-lumen echo of the near wall, leading edge of the lumen- intima echo and media-adventitia echo of the far wall. A $10 \mathrm{~mm}$ long section of the common carotid artery in the proximity of the carotid bulb was selected to 
obtain mean LD and far wall IMT. During analysis, measurement window was hidden for the reader and values were saved in a text file. Mean values of IMT and carotid LD from both the right and the left sides were used in all analyses. Aortic pulse wave velocity (PWV) was measured with applanation tonometry (SphygmoCor ${ }^{\circledR}$ system, model MM3, AtCor Medical, Sydney, Australia) over the carotid and femoral arteries. The aortic pulse wave transit times were measured by electrocardiogram-guided readings of the femoral arterial pulse waves, using the carotid arterial pulse wave as the reference site. The surface distances were estimated from the suprasternal notch to the carotid and femoral measurement sites, using measuring-tape that was stretched in order not to get additional distance due to large chest or abdomen, respectively. PWV was calculated by dividing the surface distance with the pulse wave transit time yielding $\mathrm{m} \times \mathrm{s}^{-1}$. There were three biomedical scientists performing all vascular measurements. Intra-individual CV for IMT measurements was $10.4 \%$ and for PWV $8.1 \%$.

\section{Statistics}

SPSS for Windows 16.0 (SPSS inc. Chicago, IL, USA) was used for statistical analyses. Variables with skewed distribution IL-6, IL-10, CRP were log transformed. Pearson correlation coefficients were calculated between the different measurements, using bivariate correlation analysis. Statistical significance was assumed when $p<0.05$. In multiple linear regression analyses with IMT or PWV, as dependent variables, the increase of one unit for each of the variables explored, conferred a change in IMT or PWV respectively expressed as the regression coefficient (beta) with 95 percent confidence intervals (CI). In stepwise linear regression criteria for entry were $\mathrm{p}<0.05$ and for removal $\mathrm{p}>0.1$. 


\section{Ethics}

The study, which complied with the declaration of Helsinki, was approved by the Regional Ethical Review Board in Linköping, Sweden.

\section{Results}

Two-hundred and thirteen (29\%) patients were treated with diet and exercise only and the remaining patients were treated with oral glucose-lowering agents, $n=296,(40 \%)$, or insulin alone or in combination with oral glucose-lowering agents, $n=231,(31 \%) .402(54 \%)$ patients were treated with statins. Table 1 displays the characteristics of the 740 patients according to gender. Table 2 shows Pearson correlation coefficients between different variables and PWV and IMT, respectively. The apoB/apoAI ratio, IL-6, systolic BP, WC and SAD correlated significantly to IMT. HbA1c, Diabetes duration, IL-6, IL-10, systolic BP, BMI, WC and SAD correlated significantly to PWV. Pearson correlation coefficient between IMT and PWV was $\mathrm{r}=0.097 \mathrm{p}=0.01$. As shown in Figure 1a, there were significant correlations between abdominal obesity, both measured as SAD or WC and; IMT, PWV, CRP and IL-6. When the analyses in Figure 1a were confined to patients not treated with statins $(n=402,54.5 \%)$ the significant correlation between WC and IMT was lost as well but the correlation between SAD and IMT remained ( $\mathrm{p}=0.049)$. The correlations between both WC $\mathrm{r}=0.193, \mathrm{p}=0.001$ and SAD r $=0.253, \mathrm{p}<0.001$, respectively, and PWV remained statistically significant when analyses were confined to subjects not on statins.

Figure $1 \mathrm{~b}$ and $1 \mathrm{c}$ show the analyses for men and women, respectively. In women, SAD, but not WC, was significantly associated with PWV $(\mathrm{p}<0.001)$. Neither SAD nor WC correlated 
significantly to IMT in women. In men, both SAD and WC correlated significantly to PWV and IMT, respectively, Figure 1c.

The associations from Table 2 and Figure 1 were further explored in multiple linear regression analyses shown in Table 3. Table 3a displays multiple linear regression analyses with IMT as dependent variable and age, sex, treatment with statins, SBP, CRP, HbA1c and $\mathrm{BMI}$ as independent variables. In this setting, both $\mathrm{SAD}$ and $\mathrm{WC}$ remained significantly associated with IMT.

In table $3 b$, PWV was entered as the dependent variable and age, sex, treatment with statins, SBP, CRP, HbA1c and BMI as co-variates. In this setting, IL-6, IL-10, SAD and WC remained significantly associated with PWV. When adjusting for reported hypertension and treatment with antihypertensive agents as well as glucose lowering agents the results, In both table $3 a$ and $b$, were virtually unchanged Finally in a stepwise linear regression (not in table), entering both SAD and WC as independent variables, and PWV as dependent variable, WC was removed prior to $\mathrm{SAD}$.

\section{Discussion}

To the best of our knowledge this is the first study comparing SAD and WC, exploring the associations between abdominal obesity, inflammation and markers of subclinical organ damage in middle-aged patients with type 2 diabetes. In this study we found significant associations between abdominal obesity, measured both as SAD and WC, and subclinical atherosclerosis as well as arterial stiffness. However, in most analyses SAD was more robustly associated to IMT and PWV compared to WC. There were also significant associations between both abdominal obesity and inflammatory markers, as well as between 
inflammatory markers and markers of subclinical organ damage. Interestingly, inflammatory markers were associated to PWV but not to IMT. A recent study performed in Edinburgh in a similar setting reported that inflammatory markers were not at all correlated to PWV(17) . However the patients in this study were considerably younger compared to the Edinburgh cohort and age is a major determinant of arterial stiffness. Consistent with our results CRP has several times been found significantly associated with PWV (18-19). IMT and PWV are both markers of subclinical organ damage and seem to reflect different pathways in the multifactorial pathogenesis of cardiovascular disease. Since adipose tissue produces the proinflammatory cytokine IL-6, as well as other potential atherogenic factors, there is a possible link between abdominal obesity and increased inflammatory response in the atherosclerotic process(20). In this study, we found no association between conventionally measured lipids (LDL-c and HDL-c), glycaemic control or CRP and subclinical atherosclerosis in the carotid arteries. However, we confirmed the findings from a previous analysis from a small sample ( $n=247$ ) of this study reporting on an association between the apoB/apoAI ratio and IMT (14). Since classical risk factors, such as lipid levels and smoking status show poor correlation to IMT there is a need for gaining further knowledge about clinically feasible determinants of subclinical atherosclerosis.

SAD has previously been shown to be associated with insulin resistance and inflammation equally or better compared with traditional anthropometric measurements (6). In this study we were able to confirm the above mentioned association between SAD and markers of subclinical inflammation in a population of patients with type 2 diabetes. Furthermore, we found that SAD also was associated with increased IMT and PWV in both men and women and also that, the associations was independent of age, sex, systolic blood pressure, CRP, treatment with statins, $\mathrm{HbA1c}$ and BMI. 
It would have been interesting to perform the analyses also stratified for gender. However, due to the small number of female participants compared to men, this did not seem to be relevant"

An important factor to consider in clinical practice is the reliability of the measurements, where SAD has a high reliability in both lean and obese subjects (21). WC can be measured in various ways and there is no consensus about which is the best measurement protocol (22). In this study we have chosen the method of measuring WC recommended by WHO, where WC is measured midway between the last rib and the iliac crest and not at maximum WC, compared to $\mathrm{SAD}$ which is measured at maximum abdominal height. This might partly explain our finding that SAD was more robustly associated to subclinical atherosclerosis.

The cross-sectional design of this study is its major limitation; hence we were not able to make conclusions about causality. However, we conclude that measuring abdominal obesity is a feasible measure not only for obesity, but that also provides information on the level of lowgrade systemic inflammation; atherosclerosis and arterial stiffness, in middle-aged patients with type 2 diabetes. In this study the difference between SAD and WC is quite subtle and both measurements would be useful in clinical practice. Our results also indicate that commonly used risk markers show low or no correlation to subclinical organ damage. If our results are confirmed in further prospective studies, SAD could be used as a more adequate risk-assessment tool compared to WC in clinical practice to identify patients with type 2 diabetes at high cardiovascular risk. 


\section{Acknowledgements}

This study was supported by grants from the Medical Research Council of Southeast Sweden, the Center for Medical Image Science and Visualization (CMIV), Linkoping University, Futurum, GE Healthcare and the Swedish Heart-Lung Foundation and the Swedish Research Council Grant 12661 (Clinical-Trials.gov number, NCT 01049737)

\section{Conflict of interest}

The authors declare no conflicts of interests 


\section{References}

1. Laakso M, Lehto S. Epidemiology of risk factors for cardiovascular disease in diabetes and impaired glucose tolerance. Atherosclerosis. 1998 Apr;137 Suppl:S65-73. 2. Pickup JC, Mattock MB, Chusney GD, Burt D. NIDDM as a disease of the innate immune system: association of acute-phase reactants and interleukin- 6 with metabolic syndrome X. Diabetologia. 1997 Nov;40(11):1286-92.

3. Steinberg D. Atherogenesis in perspective: hypercholesterolemia and inflammation as partners in crime. Nat Med. 2002 Nov;8(11):1211-7.

4. Lin CP, Lin WT, Leu HB, Wu TC, Chen JW. Differential mononuclear cell activity and endothelial inflammation in coronary artery disease and cardiac syndrome X. Int J Cardiol. 2003 May;89(1):53-62.

5. Chan JM, Rimm EB, Colditz GA, Stampfer MJ, Willett WC. Obesity, fat distribution, and weight gain as risk factors for clinical diabetes in men. Diabetes Care. 1994 Sep;17(9):961-9.

6. Petersson H, Daryani A, Riserus U. Sagittal abdominal diameter as a marker of inflammation and insulin resistance among immigrant women from the Middle East and native Swedish women: a cross-sectional study. Cardiovasc Diabetol. 2007;6:10.

7. Riserus U, Arnlov J, Brismar K, Zethelius B, Berglund L, Vessby B. Sagittal abdominal diameter is a strong anthropometric marker of insulin resistance and hyperproinsulinemia in obese men. Diabetes Care. 2004 Aug;27(8):2041-6.

8. Pajunen P, Rissanen H, Laaksonen MA, Heliovaara M, Reunanen A, Knekt P. Sagittal Abdominal Diameter as a New Predictor for Incident Diabetes. Diabetes Care. 2012 Sep 6. 
cardiovascular events with carotid intima-media thickness: a systematic review and metaanalysis. Circulation. 2007 Jan 30;115(4):459-67.

10.

Amato M, Montorsi P, Ravani A, Oldani E, Galli S, Ravagnani PM, et al.

Carotid intima-media thickness by B-mode ultrasound as surrogate of coronary

atherosclerosis: correlation with quantitative coronary angiography and coronary intravascular ultrasound findings. Eur Heart J. 2007 Sep;28(17):2094-101.

11. Laurent S, Boutouyrie P. Arterial stiffness: a new surrogate end point for cardiovascular disease? J Nephrol. 2007 Nov-Dec;20 Suppl 12:S45-50.

12. Sutton-Tyrrell K, Najjar SS, Boudreau RM, Venkitachalam L, Kupelian V, Simonsick EM, et al. Elevated aortic pulse wave velocity, a marker of arterial stiffness, predicts cardiovascular events in well-functioning older adults. Circulation. 2005 Jun 28;111(25):3384-90.

13. Wykretowicz A, Gerstenberger P, Guzik P, Milewska A, Krauze T, Adamska K, et al. Arterial stiffness in relation to subclinical atherosclerosis. Eur J Clin Invest. 2009 Jan;39(1):11-6.

14. Dahlen EM, Lanne T, Engvall J, Lindstrom T, Grodzinsky E, Nystrom FH, et al. Carotid intima-media thickness and apolipoprotein B/apolipoprotein A-I ratio in middle-aged patients with Type 2 diabetes. Diabet Med. 2009 Apr;26(4):384-90.

15. Wijkman M, Lanne T, Engvall J, Lindstrom T, Ostgren CJ, Nystrom FH.

Masked nocturnal hypertension--a novel marker of risk in type 2 diabetes. Diabetologia. 2009 Jul;52(7):1258-64.

16. Pearson TA, Mensah GA, Alexander RW, Anderson JL, Cannon RO, 3rd, Criqui M, et al. Markers of inflammation and cardiovascular disease: application to clinical 
and public health practice: A statement for healthcare professionals from the Centers for Disease Control and Prevention and the American Heart Association. Circulation. 2003 Jan 28;107(3):499-511.

17. Teoh WL, Price JF, Williamson RM, Payne RA, Van Look LA, Reynolds RM, et al. Metabolic parameters associated with arterial stiffness in older adults with Type 2 diabetes: the Edinburgh Type 2 diabetes study. J Hypertens. 2013 May;31(5):1010-7. 18. Nagano M, Nakamura M, Sato K, Tanaka F, Segawa T, Hiramori K. Association between serum C-reactive protein levels and pulse wave velocity: a populationbased cross-sectional study in a general population. Atherosclerosis. 2005 May;180(1):18995.

19. Mattace-Raso FU, van der Cammen TJ, van der Meer IM, Schalekamp MA, Asmar R, Hofman A, et al. C-reactive protein and arterial stiffness in older adults: the Rotterdam Study. Atherosclerosis. 2004 Sep;176(1):111-6.

20. Fantuzzi G, Mazzone T. Adipose tissue and atherosclerosis: exploring the connection. Arterioscler Thromb Vasc Biol. 2007 May;27(5):996-1003.

21. Nordhamn K, Sodergren E, Olsson E, Karlstrom B, Vessby B, Berglund L. Reliability of anthropometric measurements in overweight and lean subjects: consequences for correlations between anthropometric and other variables. Int J Obes Relat Metab Disord. 2000 May;24(5):652-7.

22. Ross R, Berentzen T, Bradshaw AJ, Janssen I, Kahn HS, Katzmarzyk PT, et al. Does the relationship between waist circumference, morbidity and mortality depend on measurement protocol for waist circumference? Obes Rev. 2008 Jul;9(4):312-25. 
Figure 1 Pearson correlations between SAD and waist circumference and inflammatory markers, IMT and PWV

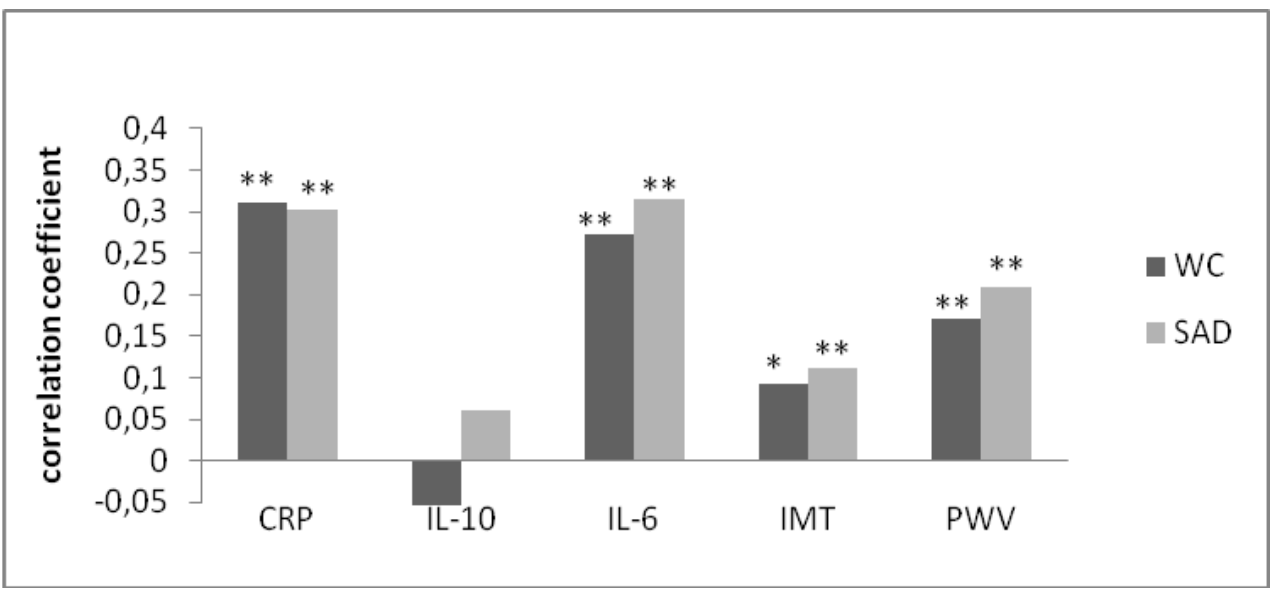

1a : 740 patients, men and women

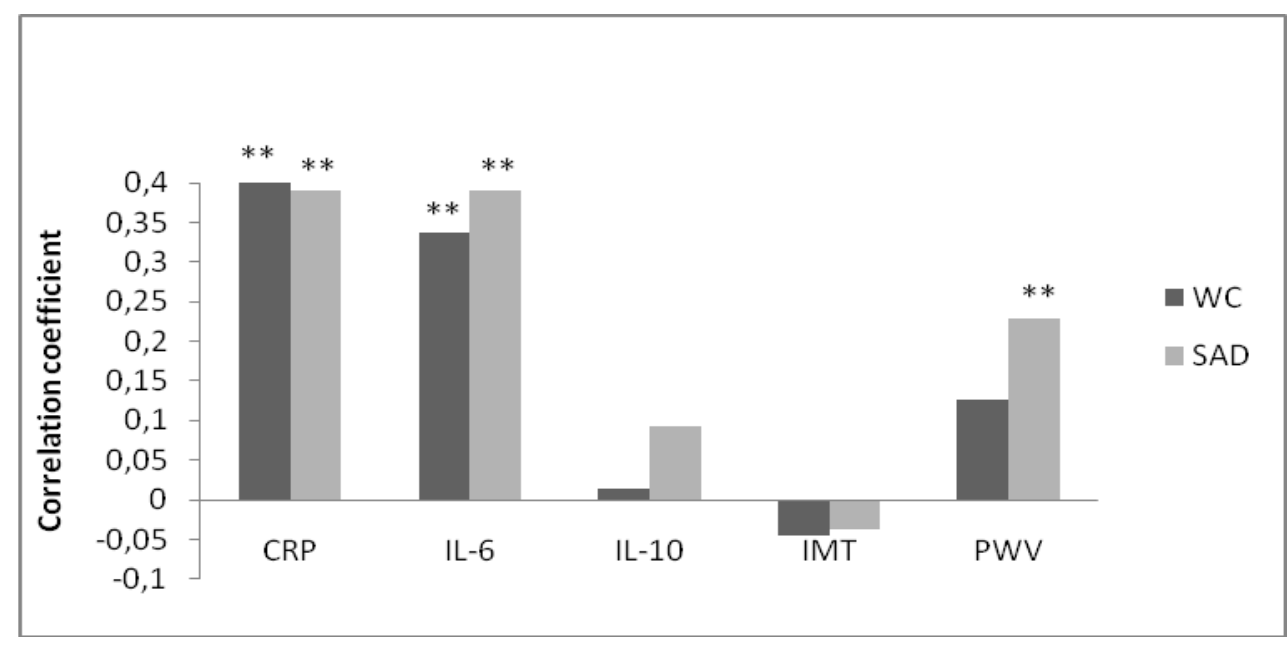

Fig 1b: 259 Women

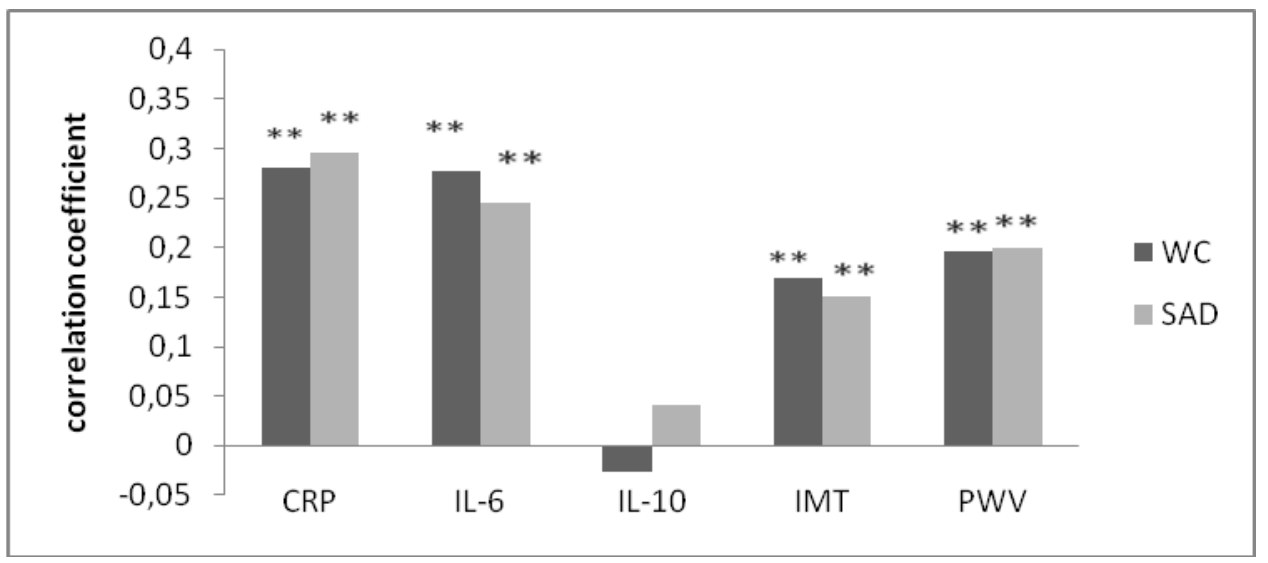

Fig 1c: 481 men

** Correlation is significant at $P \leq 0.01$ level, * Correlation is significant at $P \leq 0.05$ level

CRP: C-reactive protein; IL-10: interleukin-10, IL-6: Interleukin-6; IMT: Intima-media thickness; PWV: pulse wave velocity; SAD: Sagittal abdominal diameter; WC: Waist circumference 
Table 1. Baseline characteristics of the 740 patients with type 2 diabetes

\begin{tabular}{|c|c|c|c|c|}
\hline \multirow[t]{2}{*}{ Variable } & \multicolumn{2}{|c|}{ Men $n=481$} & \multicolumn{2}{|c|}{ Women $n=259$} \\
\hline & mean & (sd) & mean & (sd) \\
\hline Age, years & 60.9 & (3.1) & 60.7 & (3.0) \\
\hline Diabetes duration, years & 7.1 & (6.4) & 7.4 & $(5.8)$ \\
\hline BMI, $\mathrm{kg} \mathrm{m}^{-2}$ & 29.6 & $(4.2)$ & 31.0 & $(5.5)$ \\
\hline Waist circumference, $\mathrm{cm}$ & 105.0 & $(11.1)$ & 102.6 & (13.4) \\
\hline Sagittal abdominal diameter, $\mathrm{cm}$ & 25.7 & (3.7) & 25.3 & (3.9) \\
\hline Systolic BP (SBP), mm Hg & 136.7 & $(15.8)$ & 137.5 & $(17.0)$ \\
\hline Diastolic BP (DBP), mm Hg & 80.6 & (9.9) & 78.6 & $(10.0)$ \\
\hline Heart rate, bpm & 71.1 & (10.7) & 74.9 & $(10.1)$ \\
\hline fP-glucose, $\mathrm{mmol} \mathrm{L}^{-1}$ & 8.8 & $(2.7)$ & 8.7 & $(2.7)$ \\
\hline HbA1c, \% units & 6.1 & $(1.1)$ & 6.1 & $(1.1)$ \\
\hline hs-CRP*, mg L ${ }^{-1}$ & $1.9 * *$ & $(2.1)$ & $2.9^{* *}$ & $(2.4)$ \\
\hline Interleukin $6^{*}, \mathrm{pg} \mathrm{ml}^{-1}$ & 3.17 & $(6.62)$ & 3.18 & $(3.84)$ \\
\hline Interleukin $10^{*}, \mathrm{pg} \mathrm{ml}^{-1}$ & 1.20 & $(1.38)$ & 1.31 & $(2.83)$ \\
\hline Total cholesterol, $\mathrm{mmol} \mathrm{L}^{-1}$ & 4.6 & $(0.9)$ & 5.0 & $(1.0)$ \\
\hline LDL-cholesterol, mmol L ${ }^{-1}$ & 2.6 & $(0.74)$ & 2.8 & $(0.9)$ \\
\hline HDL-cholesterol, mmol L ${ }^{-1}$ & 1.2 & $(0.3)$ & 1.4 & $(0.4)$ \\
\hline nonHDL-c, mmol L & 3.4 & $(0.8)$ & 3.6 & $(1.0)$ \\
\hline Total-chol/HDL-cholesterol ratio & 3.7 & (1.0) & 3.9 & $(1.0)$ \\
\hline ApoB /ApoA-I ratio & 0.74 & $(0.16)$ & 0.72 & $(0.19)$ \\
\hline Carotid IMT, mm & 0.75 & $(0.19)$ & 0.70 & $(0.10)$ \\
\hline Carotid lumen diameter, mm & 6.77 & $(0.72)$ & 6.14 & $(0.71)$ \\
\hline Pulse wave velocity, $\mathrm{m} \mathrm{s}^{-1}$ & 10.4 & $(2.1)$ & 10.3 & $(2.2)$ \\
\hline Current smoker, n/\% & & $/ 16.1$ & $60 / 23$ & \\
\hline Previous smoker, n/\% & & $8 / 54.5$ & $101 / 3$ & \\
\hline Treatment with statins, $\mathrm{n} / \%$ & & $8 / 53.8$ & $144 / 5$ & \\
\hline Plaque in the right carotid artery, $\mathrm{n} / \%$ & & $7 / 59.9$ & $137 / 5$ & \\
\hline
\end{tabular}

*geometrical mean used in analyses

** values $>10 \mathrm{mgL}^{-1}$ have been excluded 
Table 2. Pearson correlation coefficients (r) in relation to intima media-thickness (IMT) and pulse wave velocity (PWV) in 740 middle-aged patients with type-2 diabetes.

IMT

PWV

Variable

$r$

$p$

$r$

$p$

\begin{tabular}{|c|c|c|c|c|}
\hline Age, years & 0.133 & $<0.001$ & 0.186 & $<0.001$ \\
\hline HbA1c, \% units & 0.033 & 0.377 & 0.167 & $<0.001$ \\
\hline Diabetes duration & 0.032 & 0.401 & 0.204 & $<0.001$ \\
\hline Total cholesterol, $\mathrm{mmol} / \mathrm{L}^{-1}$ & 0.023 & 0.543 & -0.007 & 0.860 \\
\hline LDL-cholesterol, mmolL ${ }^{-1}$ & 0.038 & 0.316 & -0.012 & 0.765 \\
\hline nonHDLcholesterol, mmolL ${ }^{-1}$ & 0.048 & 0.204 & 0.016 & 0.677 \\
\hline ApoB/apoA-I & 0.083 & 0.030 & -0.043 & 0.270 \\
\hline $\mathrm{IL} 6^{*}, \mathrm{pg} \mathrm{ml}{ }^{-1}$ & 0.089 & 0.021 & 0.098 & 0.001 \\
\hline IL-10 ${ }^{*}, \mathrm{pg} \mathrm{ml}^{-1}$ & 0.051 & 0.182 & 0.087 & 0.027 \\
\hline $\mathrm{CRP}^{*}, \mathrm{mg} \mathrm{L}^{-1}$ & 0.045 & 0.255 & 0.050 & 0.207 \\
\hline Systolic BP, mmHg & 0.092 & 0.009 & 0.239 & $<0.001$ \\
\hline Diastolic BP, mmHg & -0.002 & 0.948 & -0.012 & 0.748 \\
\hline BMI, $\mathrm{kg} \mathrm{m}^{-2}$ & 0.037 & 0.320 & 0.127 & 0.001 \\
\hline Waist, cm & 0.092 & 0.013 & 0.175 & $<0.001$ \\
\hline Sagittal abdominal diameter, $\mathrm{cm}$ & 0.111 & 0.003 & 0.209 & $<0.001$ \\
\hline
\end{tabular}

*Geometrical mean were used in analyses 
Table 3 Multiple linear regression with IMT (a) and PWV (b) as dependent variables and IL-6, IL-10, SAD and WC as independent variables in different settings

a.

IMT

\begin{tabular}{lllll} 
Variable & $($ Unit $)$ & Beta coefficient & $95 \% \mathrm{CI}$ & $P$ \\
\hline IL-6 & $\left(\mathrm{pg} \mathrm{ml}^{-1}\right)$ & 0.03 & $(-0.014-0.074)$ & 0.180 \\
IL-10 & $\left(\mathrm{pg} \mathrm{ml}^{-1}\right)$ & 0.03 & $(-0.019-0.081)$ & 0.330 \\
SAD & $(\mathrm{cm})$ & 0.003 & $(0.001-0.008)$ & 0.047 \\
WC & $(\mathrm{cm})$ & 0.001 & $(0.000-0.002)$ & 0.143
\end{tabular}

b.

PWV

\begin{tabular}{lllll}
\hline IL-6 & $\left(\mathrm{pg} \mathrm{ml}^{-1}\right)$ & 0.58 & $(0.17-1.16)$ & 0.024 \\
IL-10 & $\left(\mathrm{pg} \mathrm{ml}^{-1}\right)$ & 0.77 & $(0.11-1.35)$ & 0.015 \\
SAD & $(\mathrm{cm})$ & 0.10 & $(0.05-0.14)$ & 0.005 \\
WC & $(\mathrm{cm})$ & 0.04 & $(0.017-0.046)$ & 0.002 \\
\hline
\end{tabular}

Multiple linear regression analyses of, in a. IMT and in b. PWV, as dependent variables adjusted for age, sex, treatment with statins, systolic blood pressure, CRP, HbA1c and BMI. The increase of one-unit for each of the variables confer a change in IMT (a) mm and in PWV (b) $\mathrm{m} \mathrm{s}^{-1}$, expressed as the regression coefficient (Beta) with 95 percent CI. 